\title{
Economic burden of pneumonia, sepsis and meningitis among children aged up to 5 years old at a tertiary care hospital in Thailand: an input for economic evaluation of vaccination
}

\author{
Arthorn Riewpaiboon ${ }^{1^{*}}$, \\ Vimonkarn Sirisuksan ${ }^{1,2}$, \\ Supattra Rungmaitree ${ }^{3}$, \\ Kulkanya Chokephaibulkit ${ }^{3}$ \\ ${ }^{1}$ Division of Social and Administrative Pharmacy, \\ Department of Pharmacy, Faculty of Pharmacy, \\ Mahidol University, Bangkok, Thailand \\ ${ }^{2}$ Department of Pharmacy, Siriraj Hospital, \\ Mahidol University, Bangkok, Thailand \\ ${ }^{3}$ Department of Pediatrics, Siriraj Hospital, \\ Mahidol University, Bangkok, Thailand
}

*Corresponding author:

Arthorn Riewpaiboon

arthorn.rie@mahidol.ac.th

\section{KEYWORDS:}

Children, Cost of illness,

Meningitis, Pneumonia, Sepsis,

Thailand

\footnotetext{
https://www.pharmacy.mahidol.ac.th/journal/ (C) Faculty of Pharmacy, Mahidol University (Thailand) 2020
}

\begin{abstract}
Pneumonia, sepsis, and meningitis are three of the main causes of hospitalization and mortality, particularly in children under 5 years old. The economic burden associated with these illnesses is important for health policy, planning, and management. We investigated the cost of pneumonia, sepsis, and meningitis in hospitalized children younger than 5 years of age at a tertiary public hospital. The study was designed as an incidence-based cost of illness study from a societal perspective. Data were collected from medical records and prospective interviews from October to November 2014. Forty patients were included, comprising patients with pneumonia ( 35 cases), sepsis ( 3 cases), and meningitis ( 2 cases). The mean total costs (SD) of illness per episode were US $\$ 1,945(2,628)$, US $\$ 3,489(2,757)$, and US $\$ 4,855(28,360)$ for pneumonia, sepsis, and meningitis, respectively. High economic burden of pneumonia, sepsis, and meningitis in children was found. These data could help policymakers evaluate the cost-effectiveness of vaccination strategies against these illnesses.
\end{abstract}

\section{INTRODUCTION}

Pneumonia, sepsis, and meningitis are three of the main causes of hospitalization and mortality, particularly in children younger than 5 years of age. Pneumonia is the most common cause of death in children worldwide ${ }^{1}$. In 2010, the incidence of pneumonia in all age groups in Thailand was 260.17 cases per 100,000 persons, with a mortality rate of 1.53 per 100,000 persons. The incidence rate was highest in children under 5 years old at 1,939.49 per 100,000 persons ${ }^{2}$. Additionally, bacterial sepsis and meningitis are serious infections resulting in long-term morbidity and death in children ${ }^{3}$. In 2001, the incidence rate of meningitis in Thai children under 5 years of age was 24.6 cases per 100,000 persons ${ }^{4}$. The incidence rate of pneumococcal bacteremia and sepsis in children under five years of age in the Sa Kaeo and Nakhon Phanom provinces of Thailand between 2005 and 2010 was 11.7 cases per 100,000 person-years 5 .

Vaccination has been one of the most effective interventions to decrease mortality and morbidity caused by infectious diseases ${ }^{6}$. 
Pneumococcal conjugate vaccines (PCVs) have been proven safe and effective in children to prevent both invasive (e.g. meningitis, sepsis) and non-invasive (e.g. pneumonia, otitis media) pneumococcal diseases. The efficacy of the pneumococcal conjugate vaccine (PCV) was $89 \%$ in the reduction of invasive pneumococcal disease, $6 \%$ in the prevention of clinical pneumonia, and $29 \%$ in the prevention of radiograph-confirmed pneumonia ${ }^{7}$. For Haemophilus influenzae type $b$ (Hib) vaccine, safety and immunogenicity have been demonstrated. The protective efficacy of the Hib conjugate vaccine was $84 \%$ against invasive Hib disease, $75 \%$ against meningitis, and $69 \%$ against pneumonia ${ }^{8}$.

PCV and Hib vaccines are recommended for routine immunization by the World Health Organization (WHO ${ }^{9}$. Presently, the PCV and Hib vaccines are available in the Thai market ${ }^{10}$; however, they are not included in the Expanded Program of Immunization (EPI) ${ }^{11}$. In Thailand, the introduction of new vaccines is authorized by the Ministry of Public Health (MoPH) with recommendations made by the Advisory Committee on Immunization Practices (ACIP). The ACIP makes recommendations for vaccine schedules, the target population, and choices of vaccines to prevent specific diseases ${ }^{12}$. Introduction of a new vaccine depends on various aspects, including policy, regulation, clinical guidelines, expert recommendations, clinical efficacy, and economic evaluation ${ }^{13}$.

Cost of illness studies are important for estimating the economic burden of diseases on society ${ }^{14}$. Cost of illness is an important input in cost-effectiveness analysis, known as the burden of disease, which is a term that encompasses various aspects of disease impact on health outcomes in a country, specific regions, communities, and even individuals ${ }^{15,16}$. They are also useful markers for evaluating healthcare technologies. The costeffectiveness of PCVs and Hib vaccines has been evaluated in England, India, Singapore, Switzerland, Thailand, and Wales ${ }^{17-22}$. Although cost studies of pneumonia, sepsis, and meningitis have been conducted in many countries ${ }^{23-26}$, the generalizability of the results to other settings is limited due to differences in healthcare systems, attitudes, culture, and environment.

A recent study in Thailand on the cost utility of PCV-10 and PCV-13 was conducted and the vaccines were found not cost-effective ${ }^{22}$. The cost data in that evaluation involved reimbursement rates that are normally less than the economic cost in public hospital settings. For Hib vaccine, a cost-benefit analysis found that the cost of the vaccination program was higher than savings from disease prevention ${ }^{20}$. This study employed costing data published in 2002 that was not up-todate. Therefore, we aimed to explore the current empirical cost of pneumonia, meningitis, and sepsis in tertiary care from a societal perspective. The results could be used to re-evaluate costeffectiveness of the vaccines, and also to make decisions as to whether to include selected vaccines in the National EPI.

\section{MATERIALS AND METHODS}

\subsection{Study design and data collection}

The study was conducted prospectively as an incidence-based cost of illness analysis from a societal perspective. The incidence-based approach estimates the costs of new cases from diagnosis to cure or death ${ }^{27}$. The study sample included all hospitalized children aged 5 years and younger with a diagnosis of pneumonia, sepsis or meningitis at Siriraj Hospital, a tertiary care public hospital in Bangkok, who were admitted between October to November 2014. Patients with a major diagnosis of pneumonia, sepsis, and meningitis - with or without complications or a secondary diagnosis - were included in the study. Cases were excluded when (i) the patient did not receive full treatment in the hospital or was referred to the hospital; (ii) the patient could not be contacted for a follow-up interview after returning home; (iii) the primary discharge diagnosis (according to the International Classification of Diseases, $10^{\text {th }}$ revision; ICD-10) did not match the criteria for pneumonia (J12-18), bacteremia (A021, A327, A40-A41), or bacterial meningitis (A170, A320, A390, G01-G03).

The costs from a societal perspective are composed of direct medical costs (treatment cost), direct non-medical costs (travel, food, accommodation, time lost by caregivers), and indirect costs (time lost by patient) ${ }^{27}$. Direct medical costs in the hospital of study was extracted from the hospital's electronic data. The database covered resource utilization from patient bills, including medications 
and supplies, laboratory tests, surgeries, procedures, inpatient nursing care, and other hospital fees. The demographic characteristics of patients and their clinical status were also reviewed. Direct non-medical costs and indirect costs, including treatment costs before, during, and after treatment in the hospital, were collected by interviewing caregivers twice using a structured questionnaire. The first interview was conducted face-to-face during admission while the second interview was conducted via telephone seven days after hospital discharge. Informal care was estimated by asking whether anyone in the family had to stop working in order to care for the patient during illness, and if so, for how many days and at what cost per day of lost income. Duration of illness was derived from the caregiver's report of the time from when the child first became ill until full recovery.

The study was approved by the Siriraj Institutional Review Board (SiRB) for Human Research Protection. Informed consent was obtained before the interviews and prior to accessing clinical records. Patient information and questionnaires were collected and stored separately.

\subsection{Costing methods}

Cost component definitions and cost calculations are described in Table $1^{27}$. All costs are valued in 2014 US dollars (US $\$ 1=32.5$ Thai baht) ${ }^{28}$. Direct medical cost was defined as healthcarerelated costs associated with hospital treatment plus the cost of treatment before, during, and after admission. The hospital treatment costs were calculated by multiplying the billed hospital charges by the cost-to-charge ratios (CCR) (Table 2). The CCR, which were obtained from the Cost Estimation Unit of the Finance Division at Siriraj Hospital, were calculated based on the total annual expenditures of each of the hospital's service departments (excluding expenditures of its teaching school) divided by its total annual revenue.

Table 1. Cost components, definitions and cost calculations

\begin{tabular}{|c|c|c|c|}
\hline Variable & Definition & Source & Cost calculation \\
\hline Direct medical cost & \multicolumn{3}{|c|}{ Healthcare-related costs associated with medical treatments } \\
\hline Hospital treatment costs & $\begin{array}{l}\text { Medical treatments in } \\
\text { the study hospital }\end{array}$ & $\begin{array}{l}\text { Hospital electronic } \\
\text { database }\end{array}$ & $\begin{array}{l}\text { Hospital charge } \\
\times \mathrm{CCR}\end{array}$ \\
\hline $\begin{array}{l}\text { Cost of treatment before } \\
\text { and after admission }\end{array}$ & $\begin{array}{l}\text { Medical treatments } \\
\text { outside the study } \\
\text { hospital }\end{array}$ & Caregiver interviews & Actual payment \\
\hline Direct non-medical cost & \multicolumn{3}{|c|}{ Out-of-pocket expenses incurred by the patient and caregiver } \\
\hline $\begin{array}{l}\text { Foods, travel, babysitter } \\
\text { costs }\end{array}$ & $\begin{array}{l}\text { Extra cost incurred } \\
\text { because of illness }\end{array}$ & Caregiver interviews & Actual payment \\
\hline Informal care cost & $\begin{array}{l}\text { Value of the } \\
\text { caregiver's } \\
\text { productivity loss as } \\
\text { a result of child care }\end{array}$ & Caregiver interviews & $\begin{array}{l}\text { Informal care days } \times \\
\text { per capita GNI/365 }\end{array}$ \\
\hline Indirect cost & \multicolumn{3}{|c|}{ Value of the patient's productivity loss due to illness } \\
\hline Morbidity cost & $\begin{array}{l}\text { Inability to lead } \\
\text { a normal life }\end{array}$ & Caregiver interviews & $\begin{array}{l}\text { Days of illness } \times \\
\text { per capita GNI/365 }\end{array}$ \\
\hline Mortality cost & Premature death & Caregiver interviews & $\begin{array}{l}\text { (average life span }- \text { age at } \\
\text { death) } \times \text { per capita GNI }\end{array}$ \\
\hline
\end{tabular}

Note: $\mathrm{CCR}=$ cost-to-charge ratio; GNI = gross national income. 
Table 2. Cost-to-charge ratio

\begin{tabular}{lll}
\hline \multicolumn{1}{c}{ Charge group } & \multicolumn{1}{c}{ Subgroup } & Cost-to-charge ratio* \\
\hline Medical service & Rehabilitation & 1.44 \\
& Blood components & 1.08 \\
& Treatments & 2.88 \\
& & 0.98 \\
Investigation service & Laboratory & 1.08 \\
& Blood test for transfusion & 1.00 \\
& Diagnostic & 0.86 \\
& Radiology & 1.12 \\
Drugs and medical supplies & Pathology & 0.77 \\
Other charges & & 1.35 \\
Room and food charges & & 2.23 \\
\hline * Cost-to-charge ratios were calculated based on the total annual expenditures of each of the service departments in the hospital, \\
exclude expenditure of teaching school, and divided by their total annual revenue. They were provided by the Cost Estimation \\
Unit of the Finance Division at Siriraj Hospital.
\end{tabular}

Direct non-medical cost was defined as the out-of-pocket expenses incurred by both patients and caregivers, including transportation to the hospital, food, babysitting, and cost of time spent taking care of the patient (informal care). Cost of informal care can be categorized in the indirect cost or direct non-medical cost. In a cost-utility analysis (CUA) using a societal perspective, cost of time lost by patients or indirect cost is not included. However, cost of time lost by caregivers or cost of informal care must be included in the analysis. Therefore, if cost of informal care is added to the indirect cost, and then the indirect is excluded, the results of the CUA are wrong. This was demonstrated in a study on rotavirus diarrhoea ${ }^{29}$.

Indirect cost was defined as the value of productivity lost - the patient's inability to live a normal life (morbidity cost) or premature death (mortality cost). The morbidity cost was calculated by multiplying the time lost or duration of illness by the gross national income (GNI) per capita per day, or US \$15.9 (517.3 Thai baht), according to the Office of the National Economic and Social Development Board, Thailand ${ }^{30}$. The cost of residual disability was not included in the study due to limitations in detecting such disability.

\subsection{Statistical analysis}

Demographic characteristics of the patients, resource use, cost by component, and total cost of illness were analyzed using descriptive statistics. One-way sensitivity analysis was used to determine the robustness of the results. For multi-way analysis, in the best-case scenario, the minimum values of all the variables were used, while the maximum values were used in the worst-case scenario.

\section{RESULTS}

\subsection{Characteristics of interviewed patients}

Forty cases were included in the analysis: pneumonia (35 cases; $87.5 \%$ ), sepsis (3 cases; $7.5 \%$ ), and meningitis ( 2 cases; $5.0 \%$ ). The median age was 10 months for pneumonia, 9 months for sepsis, and 25 days for meningitis. The characteristics of the patients are presented in Table 3.

Two schemes of healthcare coverage were used for reimbursement by the patients: 19 cases $(47.5 \%)$ used Universal Coverage (UC), which is the default healthcare scheme provided to all Thai citizens who do not have other coverage, and 9 cases (22.5\%) used the Civil Servant Medical Benefit Scheme (CSMBS), which is provided to family members of civil servants. The other 12 cases $(30 \%)$ were out-of-pocket payments. 


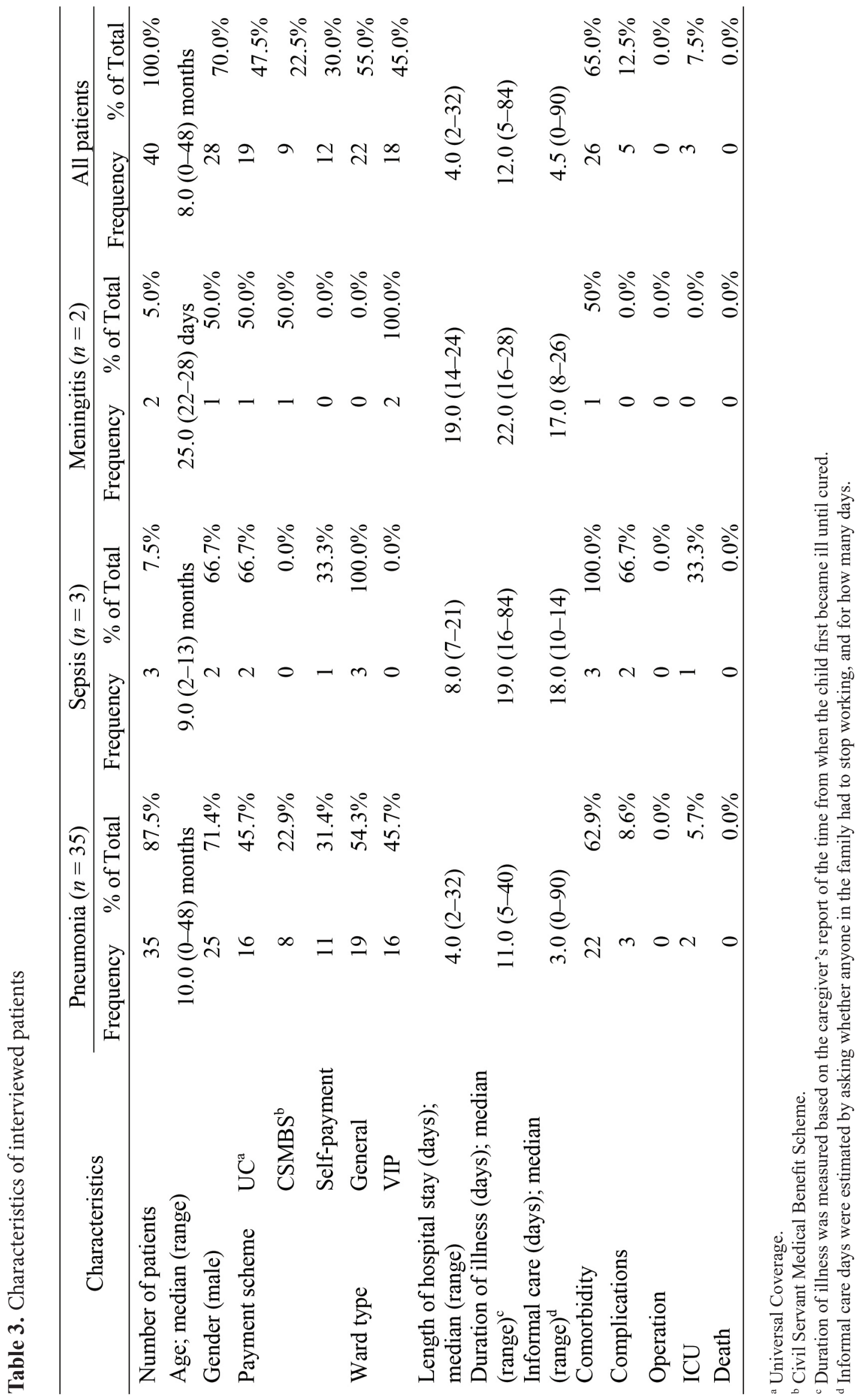


The median length of hospital stay was 4 days for pneumonia, 8 days for sepsis, and 19 days for meningitis. The median duration of illnesses was 11days for pneumonia, 19 days for sepsis, and 22 days for meningitis. For pneumonia, viral pathogens were identified in 18 cases (51.4\%), of which $10(56 \%)$ were related to respiratory syncytial virus (RSV). Complications occurred in $8.6 \%$ of patients with pneumonia and in $66.7 \%$ of those with sepsis. Two pneumonia cases and 1 sepsis case resulted in admission to the intensive care unit (ICU). None of the patients underwent surgery or died (Table 3 ).

\subsection{Total costs (per episode)}

The average (SD) total costs of pneumonia, sepsis, and meningitis were US $\$ 1,945(2,628)$, US $\$ 3,489(2,757)$ and US $\$ 4,855(28,360)$, respectively. In all of the cases, the majority of costs were attributable to direct medical cost (76.1\%), followed by direct non-medical cost (12.5\%), and indirect cost (11.4\%). Medical service cost (mainly, nursing fee) was the largest component of direct medical costs, followed by investigation cost and drug cost. Informal care cost represented the highest proportion of direct non-medical costs (Table 4).

\subsection{Sensitivity analysis}

One-way sensitivity analysis was conducted for pneumonia, but not for sepsis and meningitis due to an inadequate number of patients. The total cost of illness was most affected by the change of medical service cost, with changes in the total cost of $-30.8 \%$ and $+350.3 \%$ when replacing the average value with minimum and maximum values, respectively. This was followed by food and room cost $(-17.2 \%$ and $+84.3 \%)$, investigation cost $(-6.9 \%$ and $+93.6 \%)$, and travel cost $(-4.7 \%$ and $+90.3 \%)$, respectively. In the multi-way analysis of the bestand worst-case scenarios using the minimum and maximum values of all the variables, the average total cost was decreased from the base-case calculations by $81.3 \%$ in the best-case scenario and increased by $803.3 \%$ in the worst-case scenario.

\section{DISCUSSION}

This is the first study on the societal costs of the three major infections in children under 5 years of age in Thailand, conducted in a public hospital setting in Bangkok. Most of the pneumonia patients were younger than 1 year of age $(60 \%)$, comprising mostly males (71.4\%), which is similar to a study conducted in Sa Kaeo province, Thailand, in $2006^{31}$. The high proportion of RSV was also comparable to that found in another study on pneumonia in two Thai provinces ${ }^{32}$.

The most precise tool for hospital cost evaluation is the micro-costing method, which provides details of the resources used. However, this method is costly and time-consuming, hence, we used the CCR to adjust hospital costs in this study. Due to differences in the pricing of each service, this method may be less accurate than the micro-costing method. Nevertheless, we felt that the advantages of the CCR method (i.e. simpler and less time-consuming) outweighed the minimal potential drawbacks. Although the CCR of 1.93 in this study was comparatively higher than the findings of 1.63 and 1.45 for regional/provincial hospitals and district hospitals, respectively ${ }^{33}$, a higher CCR is to be expected in larger tertiary care centers. Moreover, most patients are referred to tertiary care centers for more serious infections, and therefore, the higher CCR in tertiary care centers would be more relevant for the three medical conditions (pneumonia, sepsis, and meningitis) investigated in this study.

In this analysis, hospital treatment costs included the cost of outpatient visits on the day of admission. This is a component that might result in a higher direct medical cost compared with other studies ${ }^{34}$. We found that $76 \%$ of the total cost was attributed to direct medical cost. This differed from some previous studies in Thailand, such as those on influenza and bacteremic melioidosis ${ }^{34,35}$. In those studies, the indirect cost was found to be higher than the direct cost, accounting for $57 \%$ of the total cost of influenza-related illness ${ }^{35}$, and $75-85 \%$ of the total cost of melioidosis ${ }^{34}$.

Moreover, residual disability was not included in this study. The cost due to disability is usually high because of the need for prolonged treatment after hospitalization, such as physical therapy in the hospital and at home. Therefore, the indirect costs in this study may be underestimated. 
Pharmaceutical Sciences Asia

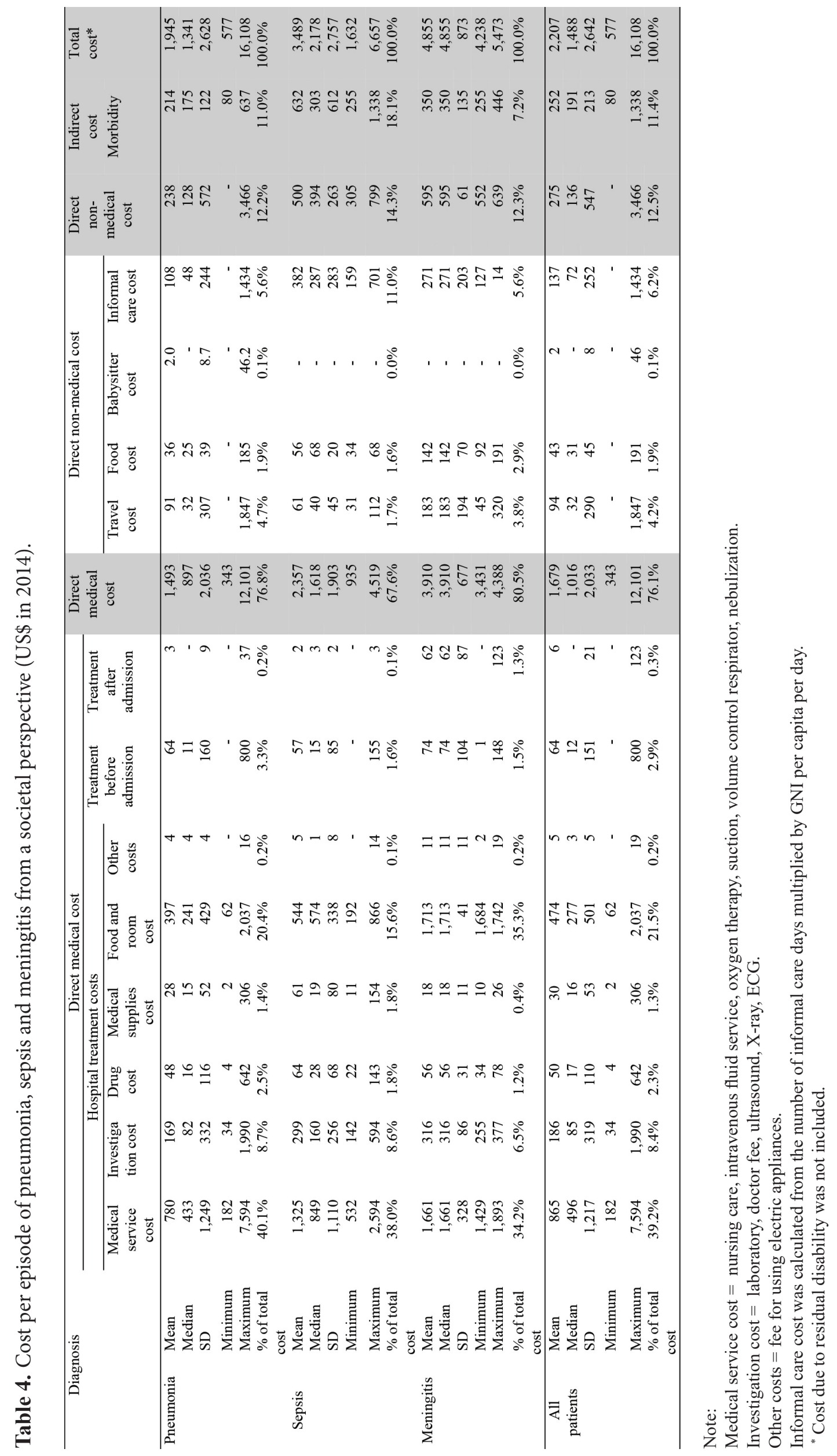


We also found that the largest component of direct medical cost was labor costs charged to patients, mainly nursing care (the highest value of medical service cost) and doctor fees (the secondhighest value of investigation cost), for all three illnesses. For pneumonia and sepsis, the medical service cost also represented the largest proportion of the total cost. The proportion of the cost components may vary in smaller hospitals that lack specialists.

Similar to this study, a study in Vietnam on the cost of pneumonia and meningitis among children less than 5 years of age at tertiary hospitals from a societal perspective, using patient's medical records and personal interviews with patients' caregivers, resulted in average total treatment costs of US \$318 for pneumonia and US \$727 for meningitis (2012 value) ${ }^{23}$. The costs were estimated from payments using a cost-to-charge ratio. Contrary to this study, the study in Vietnam covered laboratoryconfirmed and clinically diagnosed cases (different sample) and included 980 cases (larger sample size). After these costs were adjusted for the Consumer Price Index (CPI) and exchange rate ${ }^{36,37}$, the costs were US \$482 for pneumonia and US $\$ 1,101$ for meningitis (2014 value). The costs in our study were found to be higher, which could be due to the higher GNI and cost of medications and medical services in Thailand.

The authors were aware of the possibility of recall bias, which could have affected the data obtained from interviews. All interviews were conducted by trained researchers who used structured questionnaires to reduce recall bias; however, inaccuracies may still occur, especially if the interviews were not conducted soon after hospitalization.

In terms of representativeness, we checked the sample size ${ }^{38}$ by using mean and standard deviation of the results. With a precision of $20 \%$ and $30 \%$, the sample size is 138 cases and 61 cases, respectively. Due to time limitations, we reviewed only 40 cases in this study, which is another limitation of this study.

In terms of the benefits of this study, other than as an input for priority setting of health problems, these findings can be used for economic evaluation of health interventions, particularly vaccination programs. The economic evaluation of vaccination programs usually utilizes a modelling method using secondary data. As vaccination programs are usually a national policy, the data inputs require nationwide representations. As such, costs of providing services and proportion of service usage at different levels of health facilities is required. In order to obtain these costs, using estimations by adjustments is acceptable. For instance, we can estimate costs at provincial and district hospitals from the costs at the teaching hospital based on rate of payment per relative weight (RW). At a rate of $1 \mathrm{RW}$, costs at the teaching hospital, provincial hospital and district hospital are 12,000 Thai baht, 10,000 Thai Baht and 8,000 Thai baht, respectively. Based on the cost at the teaching hospital of US $\$ 2,207$, the costs at provincial hospital and district hospital are estimated at $2,207 \times(10,000 / 12,000)=\mathrm{US}$ $\$ 1,839$ and $2,207 \times(8,000 / 12,000)=$ US $\$ 1,471$, respectively. In addition, the health economics methods can compensate for a limitation of a small sample size by the use of probabilistic sensitivity analysis (PSA). The PSA repeats the analysis, normally 10,000 times, using random cost values from the mean and range of variability, which results in probability of the cost-effectiveness results. This approach has been employed in a previous study in Thailand ${ }^{29}$.

\section{CONCLUSION}

Pneumonia, meningitis, and sepsis are a significant economic and health burden in young children. High medical costs were found for all three conditions. Although the information used was from one tertiary hospital, the results can be adjusted for other levels of health facilities and used for economic evaluation of health interventions via a modelling technique with probabilistic sensitivity analysis. Therefore, the cost analysis from this study could be useful for hospital management, and evaluation and development of preventive strategies.

\section{ACKNOWLEDGEMENTS}

The authors would like to thank all participants who provided information. The authors are grateful for the dedicated support from the staff of the Cost Estimation Unit of the Finance Division, the Division of Information Technology, and the Department of Pediatrics, Siriraj Hospital, Mahidol University. 


\section{Conflict of interest}

We have no conflict of interest.

\section{Funding}

Research grant from the Master of Science Program on Social, Economic and Administrative Pharmacy, Faculty of Pharmacy and Faculty of Graduate Studies, Mahidol University.

\section{Ethical approval}

The study was approved by the Siriraj Institutional Review Board (SiRB) for Human Research Protection.

\section{Article info:}

Received July 8, 2019

Received in revised form October 30, 2019

Accepted November 2, 2019

\section{REFERENCES}

1. Liu L, Oza S, Hogan D, Perin J, Rudan I, Lawn JE, et al. Global, regional, and national causes of child mortality in 2000-13, with projections to inform post-2015 priorities: an updated systematic analysis. Lancet. 2015;385(9966): 430-40.

2. Kaewnorkkao V. Situation of pneumonia, Thailand, 2005-2010 Weekly Epidemiological Surveillance Report. 2012;43(Supplement): 9-98 (In Thai).

3. Barichello T, Fagundes GD, Generoso JS, Elias SG, Simoes LR, Teixeira AL. Pathophysiology of neonatal acute bacterial meningitis. J Med Microbiol. 2013;62(Pt 12):1781-9.

4. Muangchana C, Chunsuttiwat S, Rerks-Ngarm S, Kunasol P. Bacterial meningitis incidence in Thai children estimated by a rapid assessment tool (RAT). Southeast Asian J Trop Med Public Health. 2009;40(3):553-62.

5. Rhodes J, Dejsirilert S, Maloney SA, Jorakate P, Kaewpan A, Salika P, et al. Pneumococcal Bacteremia Requiring Hospitalization in Rural Thailand: An Update on Incidence, Clinical Characteristics, Serotype Distribution, and Antimicrobial Susceptibility, 2005-2010. PLoS One. 2013;8(6):e66038.

6. Muzumdar JM, Cline RR. Vaccine supply, demand, and policy: a primer. J Am Pharm Assoc. 2009;49(4):e87-99.

7. Pavia M, Bianco A, Nobile CG, Marinelli P,
Angelillo IF. Efficacy of pneumococcal vaccination in children younger than 24 months: a meta-analysis. Pediatrics. 2009;123(6): e1103-10.

8. Obonyo CO, Lau J. Efficacy of Haemophilus influenzae type $\mathrm{b}$ vaccination of children: $\mathrm{a}$ meta-analysis. Eur J Clin Microbiol Infect Dis. 2006;25(2):90-7.

9. Immunization Vaccines and Biologicals. WHO recommendations for routine immunization summary tables. 2016 [cited 2016 November 30]; Available from: http:/www.who.int/ immunization/policy/immunization_tables/en/

10. Bureau of Drug Control. Registered vaccine. 2016 [cited 2016 June 23]; Available from: http://drug.fda.moph.go.th/zone_search/sea 006.asp

11. Bureau of General Communicable Diseases. Standard practice of national immunization; fiscal year 2015 Department of Disease Control, Ministry of Public Health; 2015.

12. Muangchana $\mathrm{C}$, Thamapornpilas $\mathrm{P}$, Karnkawinpong $\mathrm{O}$. Immunization policy development in Thailand: The role of the Advisory Committee on Immunization Practice. Vaccine. 2010;28S: A104-9.

13. Gilca V, Sauvageau C, McNeil S, Gemmill IM, Dionne M, Dobson S, et al. Setting priorities for new vaccination programs by using public health officers and immunization managers opinions. Vaccine. 2008;26(33):4204-9.

14. Larg A, Moss JR. Cost-of-illness studies: a guide to critical evaluation. Pharmacoeconomics. 2011;29(8):653-71.

15. Jo C. Cost-of-illness studies: concepts, scopes, and methods. Clin Mol Hepatol. 2014;20(4): 327-37.

16. Hodgson TA. Costs of illness in cost-effectiveness analysis. A review of the methodology. Pharmacoeconomics. 1994;6(6):536-52.

17. Tyo KR, Rosen MM, Zeng W, Yap M, Pwee KH, Ang LW, et al. Cost-effectiveness of conjugate pneumococcal vaccination in Singapore: comparing estimates for 7-valent, 10-valent, and 13-valent vaccines. Vaccine. 2011;29(38): 6686-94.

18. Melegaro A, Edmunds WJ. Cost-effectiveness analysis of pneumococcal conjugate vaccination in England and Wales. Vaccine. 2004;22(3132):4203-14. 
19. Ess SM, Schaad UB, Gervaix A, Pinosch S, Szucs TD. Cost-effectiveness of a pneumococcal conjugate immunisation program for infants in Switzerland. Vaccine. 2003;21(23):3273-81.

20. Muangchana $C$, Warinsatian P. Incorporation of private demand into cost-benefit analysis of a universal Hib vaccination program in Thailand. Southeast Asian J Trop Med Public Health. 2011;42(2):376-87.

21. Gupta M, Prinja S, Kumar R, Kaur M. Costeffectiveness of Haemophilus influenzae type $\mathrm{b}$ (Hib) vaccine introduction in the universal immunization schedule in Haryana State, India. Health Policy Plan. 2013;28(1):51-61.

22. Kulpeng W, Leelahavarong P, Rattanavipapong W, Sornsrivichai V, Baggett HC, Meeyai A, et al. Cost-utility analysis of 10- and 13-valent pneumococcal conjugate vaccines: protection at what price in the Thai context? Vaccine. 2013;31(26):2839-47.

23. Anh DD, Riewpaiboon A, Tho le H, Kim SA, Nyambat B, Kilgore P. Treatment costs of pneumonia, meningitis, sepsis, and other diseases among hospitalized children in Viet Nam. J Health Popul Nutr. 2010;28(5):436-42.

24. Temple B, Griffiths UK, Mulholland EK, Ratu FT, Tikoduadua L, Russell FM. The cost of outpatient pneumonia in children $<5$ years of age in Fiji. Trop Med Int Health. 2012;17 (2): 197-203.

25. Keitel K, Alcoba G, Lacroix L, Manzano S, Galetto-Lacour A, Gervaix A. Observed costs and health care use of children in a prospective cohort study on community-acquired pneumonia in Geneva, Switzerland. Swiss Med Wkly. 2014;144:w13925.

26. Alvis-Guzman N, Orozco-Africano J, PaterninaCaicedo A, Coronell-Rodriguez W, AlvisEstrada L, Jervis-Jalabe D, et al. Treatment costs of diarrheal disease and all-cause pneumonia among children under-5 years of age in Colombia. Vaccine. 2013;31 Suppl 3:C58-62.

27. Riewpaiboon A. Measurement of costs for health economic evaluation. J Med Assoc Thai. 2014;97(Suppl. 5):S17-26.

28. Bank of Thailand. Rates of exchange of commercial banks in Bangkok metropolis [cited 2016 September 4]; Available from:
https://www.bot.or.th/English/Statistics/ FinancialMarkets/ExchangeRate/Pages/ StatExchangeRate.aspx

29. Muangchana C, Riewpaiboon A, Jiamsiri S, Thamapornpilas P, Warinsatian P. Economic analysis for evidence-based policy-making on a national immunization program: A case of rotavirus vaccine in Thailand. Vaccine. 2012; 30(18):2839-47.

30. Office of the National Economic and Social Development Board. National Income of Thailand 2014 Chain Volume Measures. 2016 [cited 2016 November 30]; Available from: http://www.nesdb.go.th/ewtadmin/ewt/nesdb_en/ ewt_news.php?nid=4294\&filename $=$ national_ account

31. Olsen SJ, Laosiritaworn Y, Siasiriwattana S, Chunsuttiwat S, Dowell SF. The incidence of pneumonia in rural Thailand. Int J Infect Dis. 2006;10(6):439-45.

32. Olsen SJ, Thamthitiwat S, Chantra S, Chittaganpitch M, Fry AM, Simmerman JM, et al. Incidence of respiratory pathogens in persons hospitalized with pneumonia in two provinces in Thailand. Epidemiol Infect. 2010; 138(12):1811-22.

33. Riewpaiboon A. Standard cost lists for health economic evaluation in Thailand. J Med Assoc Thai. 2014;97(Suppl. 5):S127-34.

34. Bhengsri S, Lertiendumrong J, Baggett HC, Thamthitiwat S, Chierakul W, Tisayaticom $\mathrm{K}$, et al. Economic burden of bacteremic melioidosis in eastern and northeastern, Thailand. Am J Trop Med Hyg. 2013;89(2): 369-73.

35. Simmerman JM, Lertiendumrong J, Dowell SF, Uyeki T, Olsen SJ, Chittaganpitch M, et al. The cost of influenza in Thailand. Vaccine. 2006;24(20):4417-26.

36. General Statistics Office of Vietnam. Consumer price index. 2016 [cited 2015 March 5]; Available from: http://gso.gov.vn/default_en. aspx?tabid $=780$

37. Vietcom Bank. Exchange rate. [cited 2016 November 30]; Available from: www. vietcombank.com.vn/

38. Thompson S. Sampling. 2nd ed. New York: John Wiley \& Sons; 2002. 